Trachoma

\section{What more is there to learn about trachoma?}

\section{Melese, W Alemayehu, B Gaynor, E Yi, J P Whitcher, T M Lietman}

\section{There is hope that trachoma will be the first major bacterial disease eliminated by a worldwide effort}

A few minutes spent searching Medline reveals some interesting trends: while the total number of scientific publications has exploded over the past 35 years, the number of papers incorporating the keyword "trachoma" has actually decreased (Fig lA). The number of reviews of trachoma, however, has increased (Fig 1B). Is this a sign that the study of trachoma has maturedthat effective treatments are well known and that the only challenge left is to implement them? Many recent editorials have indeed suggested that a wide variety of treatments are effective. ${ }^{1-6}$ In fact, studies suggest that trachoma is disappearing even in the absence of a programme specifically targeting the disease. $^{7-10}$ Is the war against trachoma, or at least the scientific part, finally over?

The past decade has witnessed numerous advances in chlamydia research: the chlamydial genome has been sequenced, ${ }^{11}$ diagnosis with sensitive nucleic acid amplification tests has become routine, ${ }^{12-14}$ and randomised clinical trials have purported to demonstrate the efficacy of behavioural, ${ }^{15}$ pharmacological, ${ }^{16}$ and even entymological ${ }^{17}$ control measures in reducing the prevalence of trachoma. A course of three doses of oral azithromycin administered to all members of a community was shown to be as effective as a 6 week course of topical tetracycline. ${ }^{18}$ This is important because compliance with oral azithromycin is clearly far superior. Another trial suggested that an intensive face washing programme helped reduce the severity, if not the prevalence, of active disease. ${ }^{15}$ Chemical fly control in a village not only reduces the number of eye-seeking flies (Musca sorbens), but also may have an effect on the prevalence of active trachoma. ${ }^{17}$

Is trachoma this easy to eradicate? As revolutionary as these studies have been, there are reasons why the success observed in research studies may not be achieved in an actual trachoma programme. A research programme that can concentrate on a small number of villages can achieve higher coverage of the population than national programmes that must spread their attention over hundreds of villages. Some research investigators have done such a thorough job of enrolling and treating patients that they have covered over $95 \%$ of the intended population. ${ }^{18}$ Trachoma programmes however have had coverage of $80 \%{ }^{19}$ or even less. Mathematical models imply that coverage will be one of the key determinants of whether infection can be progressively reduced with repeated periodic treatments. ${ }^{20}$
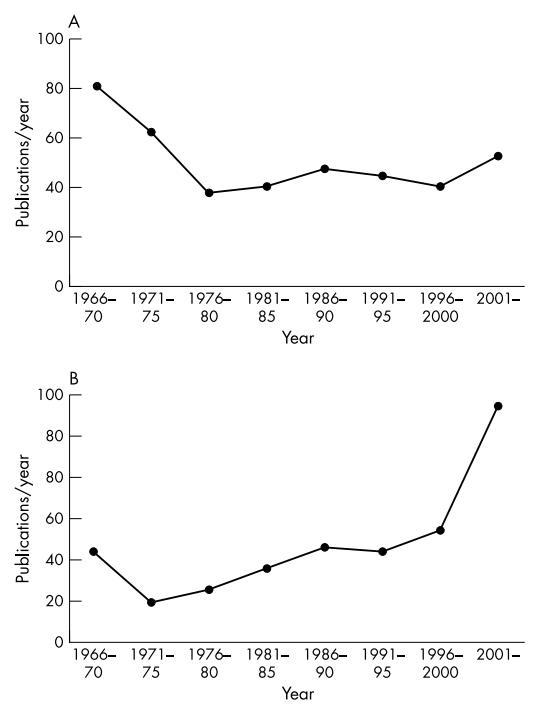

Figure 1 The number of references per year to "trachoma" (A), and to "trachoma AND review" (B) in Medline, from 1966-2002. There are now fewer publications, but a surge in reviews.

Many recent studies have been performed in areas with only modest amounts of disease, including Nepal, ${ }^{19}$ Morocco, ${ }^{21}$ Vietnam, and Saudi Arabia. ${ }^{22}$ Even an intervention that has a weak effect may be able to overcome a modest burden of infection. For example, models imply that a control measure such as mass antibiotic treatments every 2 years could progressively reduce infection in a hypoendemic community, but would have little effect in a hyperendemic area. $^{20}$ Testing an intervention in only the most hyperendemic villages in an area with a spectrum of disease may solve this problem, but it introduces another. Over time, villages with the highest prevalence should naturally "regress to the mean" even in the absence of treatment, once again leading to an overestimation of the treatment effect. ${ }^{23}$

Any treatment appears favourable in the presence of a secular trend of decreasing disease prevalence. It has been recognised that trachoma can disappear as economic conditions improve, as seen in Malawi $^{9}$ and the Gambia. ${ }^{7}$ Research in western Nepal has demonstrated that this can happen even over the course of a few years, far more quickly than many had previously believed. ${ }^{10}$ Very few studies have controlled for a possible secular trend.

While various factors such as these may have contributed to the overestimation of the success of previous studies, these factors probably do not fully explain the observed success of interventions. A recent Cochrane Collaboration review of trachoma studies revealed essentially no articles that fulfilled all of the criteria for a proper randomised controlled trial; however, the review did concede that there is evidence that some measures reduce active trachoma. ${ }^{24} \mathrm{Ex}$ perts brought together by the World Health Organization (WHO) and the International Trachoma Initiative likewise believe that trachoma programmes can drastically reduce the prevalence of disease. $^{21}$

Many questions about trachoma still remain unanswered. Firstly, we need to determine if the proposed treatments are effective in hyperendemic areas, and if so, how effective. These are the areas which need help the most, where trachoma is not disappearing on its own, and where the disease causes almost as much blindness as cataract. For example, in some areas of Ethiopia, essentially every child has signs of infection and every adult signs of past infection. ${ }^{25}{ }^{26}$ In these areas, blinding complications from trachoma are common and cause as much visual disability as cataract. Why this is the case raises many questions, including who is most at risk for complications, what is the role of severity of infection in the recurrence rate, what is the role of reinfection, and what are the reasons for recurrence of the disease after administering antibiotics. The tragic fact remains that, unlike cataract, trachoma is a preventable disease where once vision is lost it cannot in practice be regained.

It is humbling that even though trachoma has been recognised as a cause of blindness for over 3500 years, we are not yet certain how it is transmitted. Every medical student "knows" that flies are a vector for trachoma (along with fingers and fomites). However, in the 
Gambia even sensitive nucleic acid amplification tests detect chlamydia on only $0.5 \%$ of face flies. ${ }^{27}$ This is within the expected false positive rate for the tests. ${ }^{28}$ If flies are indeed a vector, then it may be easier to demonstrate this in a hyperendemic area.

We have learned a great deal about trachoma control in the past decade, and most trachoma investigators are optimistic that the WHO's stated goal of eliminating blinding trachoma will be achieved by the year 2020. However, we still have much to learn about this ancient disease. The treatments that have shown success in areas with modest trachoma need to be tested in the areas most affected by disease-in the areas where treatment is needed the most. We need to develop a rationale for repeated mass antibiotic administrations; we have to show that we can eliminate ocular chlamydia locally, that mass community treatments have a long term effect, or that other measures can reduce the prevalence of infection in hyperendemic areas. To paraphrase a leprosy researcher, the real challenge may be to determine why trachoma is disappearing before it is all gone (Paul Fine, personal communication). It has been over 20 years since the WHO declared that smallpox had been eradicated. There is hope that trachoma will be the first major bacterial disease eliminated by a worldwide effort. If so, we should learn what we can from its elimination.

Br J Ophthalmol 2003;87:521-522

\section{ACKNOWLEDGEMENTS}

We thank the Bernard Osher Foundation for its support in making this editorial possible.

\section{Authors' affiliations \\ M Melese, W Alemayehu, ORBIS \\ International, Ethiopia \\ B Gaynor, E Yi, J P Whitcher, T M Lietman, \\ FI Proctor Foundation and the Department of \\ Ophthalmology, University of California, San \\ Francisco, USA}

Correspondence to: John P Whitcher, MD, Department of Ophthalmology, FI Proctor Foundation, University of California, San Francisco, 95 Kirkham Street, Room 308, San Francisco, CA 94143-0944, USA; nepal@itsa.ucsf.edu

\section{REFERENCES}

1 Lietman T. Trachoma control: the beginning of the end? Ophthalmology 2001;108:2163-4.

2 Lietman T, Fry A. Can we eliminate trachoma? Br J Ophthalmol 2001;85:385-7.

3 Bailey R, Lietman T. The SAFE strategy for the elimination of trachoma by 2020: will it work? Bull World Health Organ 2001;79:233-6.

4 Taylor HR. A trachoma perspective. Ophthalmic Epidemiol 2001;8:69-72.

5 Taylor KI, Taylor HR. Distribution of azithromycin for the treatment of trachoma. $\mathrm{Br}$ J Ophthalmol 1999;83:134-5.

6 Taylor H. Towards the global elimination of trachoma. Nat Med 1999;5:492-3.

7 Dolin PJ, Faal H, Johnson GJ, et al. Reduction of trachoma in a sub-Saharan village in absence of a disease control programme. Lancet 1997;349:1511-12.

8 Lewallen S, Courtright P. Blindness in Africa: present situation and future needs. $\mathrm{Br}$ Ophthalmol 2001;85:897-903.

9 Hoechsmann A, Metcalfe N, Kanjaloti S, et al. Reduction of trachoma in the absence of antibiotic treatment: evidence from a population-based survey in Malawi. Ophthalmic Epidemiol 2001;8: 145-53.

10 Jha H, Chaudary J, Bhatta R, et al. Disappearance of trachoma in western $\mathrm{Nepal}$ Clin Infect Dis 2002;35:765-8

11 Stephens RS, Kalman S, Lammel C, et al. Genome sequence of an obligate intracellular pathogen of humans: Chlamydia trachomatis. Science 1998;282:754-9.

12 Dean D, Patton M, Stephens RS. Direct sequence evaluation of the major outer membrane protein gene variant regions of Chlamydia trachomatis subtypes $D^{\prime} \mathrm{I}^{\prime}$ and $\mathrm{L}^{\prime}$ '. Infect Immun 1991;59:1579-82.

13 Bobo LD, Novak N, Muñoz B, et al. Severe disease in children with trachoma is associated with persistent Chlamydia trachomatis infection. J Infect Dis 1997; 176: 1524-30.

14 Bailey RL, Hayes L, Pickett $M$, et al. Molecular epidemiology of trachoma in a Gambian village. BrJ Ophthalmol 1994;78:813-7.

15 West S, Muñoz B, Lynch M, et al. Impact of face-washing on trachoma in Kongwa Tanzania. Lancet 1995;345:155-8.

16 Bailey RL, Arullendran P, Whittle HC, et al. Randomised controlled trial of single-dose azithromycin in treatment of trachoma. Lancet 1993;342:453-6.

17 Emerson PM, Lindsay SW, Walraven GE, et al. Effect of fly control on trachoma and diarrhoea. Lancet 1999;353:1401-3.

18 Schachter J, West SK, Mabey D, et al. Azithromycin in control of trachoma. Lancet 1999;354:630-5.

19 Holm SO, Jha HC, Bhatta RC, et al. Comparison of two azithromycin distribution strategies for controlling trachoma in Nepal. strategies for controlling trachoma in Nepal.

20 Lietman T, Porco T, Dawson C, et al. Global elimination of trachoma: how frequently should we administer mass chemotherapy? Nat Med 1999:5:572-6.

21 Negrel AD, Mariotti SP. WHO alliance for the global elimination of blinding trachoma and the potential use of azithromycin. Int $J$ and the potential use of azithromycin.

22 Tabbara KF, Abu-el-Asrar A, al-Omar O, et al. Single-dose azithromycin in the treatment of trachoma. A randomized controlled study. Ophthalmology 1996;103:842-6.

23 Bonate P. Analysis of pretest-postest designs. Boca Raton: Chapman and Hall/CRC, 2000.

24 Mabey D, Fraser-Hurt N. Trachoma. BM 2001;323:218-21.

25 Alemayehu W, Chierne A. In: Kloos, Zein, eds. Health and disease in Ethiopia. West View Press, 1993.

26 Cerulli L, Cedrone C, Assefa C, et al. Epidemiological study on trachoma in two regions of Ethiopia. Rev Int Trach Pathol Ocul Trop Subtrop Sante Publique 1981;3-4:147-55.

27 Emerson PM, Bailey RL, Mahdi OS, et al. Transmission ecology of the fly Musca sorbens a putative vector of trachoma. Trans $R$ Soc Trop Med Hyg 2000;94:28-32.

28 Schachter J. In: Stephens R, ed. Ninth International Symposium on Human Chlamydial Infection. Napa, California, 1998:577-86. 